\title{
OS EDUCADORES FRANCESES CÉLESTIN FREINET E FERNAND DELIGNY
}

\author{
LOS EDUCADORES FRANCESES CÉLESTIN FREINET Y FERNAND DELIGNY
}

\author{
THE FRENCH EDUCATORS CÉLESTIN FREINET ANDFERNAND DELIGNY
}

\author{
Sônia Regina da Luz MATOS ${ }^{1}$
}

\begin{abstract}
RESUMO: O artigo é parte do estudo teórico-conceitual do projeto de pesquisa de pósdoutorado. A investigação retoma as contribuições pedagógicas dos educadores francês Célestin Freinet (1896-1966) e Fernand Deligny (1913-1996). Ambos participaram da primeira guerra mundial, foram comunistas e viveram sobre as forças dos tempos da escola nova francesa. Essas três ligações: histórica, política e educacional produziram afeitos diferentes em suas pedagogias. Sendo assim, este trabalho não pretende compará-los, e sim, valorizar as ideias e de uma certa maneira homenagear estes dois educadores do século XX. Os objetivos do texto são de identificar alguns movimentos biográficos destes educadores e mostrar os seus principais conceitos pedagógicos: Freinet, a expressão livre e Deligny, a cartografia.
\end{abstract}

PALAVRAS-CHAVE: Freinet. Expressão livre. Deligny. Cartografia.

RESUMEN: El artículo es parte del estudio teórico-conceptual del proyecto de investigación de posdoctorado. La investigación retoma las contribuciones pedagógicas de los educadores francés Célestin Freinet (1896-1966) y Fernand Deligny (19131996). Ambos participaron de la primera guerra mundial, fueron comunistas y vivieron sobre las fuerzas de los tiempos de la escuela nueva francesa. Esas tres conexiones: histórica, política y educacional produjeron efectos diferentes en sus pedagogías. Siendo así, este trabajo no pretende compararlos, y sí, valorar las ideas y de una correcta manera homenajear estos dos educadores del siglo XX. Los objetivos del texto son de identificar algunos movimientos biográficos de estos educadores y mostrar sus principales conceptos pedagógicos: Freinet, la expresión libre y Deligny, la cartografía.

PALAVRAS CLAVE: Freinet. Expresión libre. Deligny. Cartografía.

ABSTRACT: This article is part of the theoretical-conceptual study of the postdoctoral research project. In order to carry out this project it was necessary to refer to new French school thinkers and educators Célestin Freinet (1896-1966) and Fernand Deligny (1913-1996). Both Freinet and Deligny were communists, participated in World War I, and lived the forces of the new French school. However, these three

${ }^{1}$ Universidade de Caxias do Sul (UCS), Caxias do Sul - RS - Brasil. Docente. E-mail: srlmatos@ucs.br.

RIAEE - Revista Ibero-Americana de Estudos em Educação, Araraquara, v.12, n.4, p.2231-2244, out./dez. 2017. 
similarities, political, historical, and educational, had different impact on their pedagogies. Thus, this paper is not intended to compare them; it aims to value their pedagogies and, in some way, honor these two $20^{\text {th }}$. This text intends to identify some biographical movements of these educators and to show their main pedagogical concepts: Freinet the free expression, Deligny the cartography.

KEYWORDS: Freinet. Free expression. Cartography. Deligny

\section{Introdução}

O presente texto tem como tema as contribuições pedagógicas do pensamento dos educadores francês Célestin Freinet (1896-1966) e Fernand Deligny (1913-1996). Freinet e Deligny, ambos participaram da primeira guerra mundial, foram comunistas e viveram sobre as forças dos tempos da escola nova francesa. Essas três ligações: da histórica, da política e da educação produziram efeitos diferentes em suas pedagogias.

Então, o texto não pretende compará-los, o que ele quer é valorizar as ideias e de uma certa maneira estender uma homenagem a estes dois educadores do século XX. Sendo assim, os objetivos do texto são de identificar alguns movimentos biográficos destes educadores e mostrar os seus principais conceitos em seu pensamento pedagógico. Com isto, a decisão foi de elaborar um texto com dois momentos distintos, sem os cruzar em nenhum momento, para assim, efetivamente valorizarmos suas potencialidades profissionais e demarcar suas possibilidades pedagógicas.

\section{Um pouco de Célestin Freinet}

Ele, instituteur e certamente um dos mais conhecidos pedagogos franceses do século XX. Nasceu numa pequena comunidade na região dos alpes marítimos. Na juventude é chamado para se engajar na primeira guerra mundial. Diretamente nas trincheiras se feriu. Ferimento que o impossibilitou de expressar a fala por mais que alguns minutos. Isto o motivou a procurar outros modos de trabalho como educador. A experiência da guerra o mostrou uma faceta cruel da humanidade e dos homens, diante desta impactante experiência, se lança na educação das crianças populares e investe no potencial de ações educativas de solidariedade e de ajuda mútua.

Ao tratamos de uma pedagogia de Freinet e dele como educador, estamos incluindo no estudo sobre Freinet a educadora Élise Lagier Freinet (1898-1983). Ela é tomada nos clássicos de educação como a esposa do educador Freinet. O que para nós,

RIAEE - Revista Ibero-Americana de Estudos em Educação, Araraquara, v.12, n.4, p. 2231-2244, out./dez. 2017. 
neste texto, a deslocamos como uma educadora que é parte colaborativa e ativa na produção da Escola Freinet (FREINET, 1983).

Élise Freinet, institutrice na École Normale de Gap, participante do partido comunista, encontra Célestin Freinet neste espaço político. Ela se dedica aos estudos na academia de pintura. Muitas das produções intelectuais assinadas pelo autor, seu esposo, ganha a coragem e a audácia do pensamento dela, principalmente no que tangenciam as questões de produção da "expressão livre" (FREINET, 1983). Um dos conceitos cunhado fortemente na prática da pedagogia de Freinet. Durante os anos cinquenta ela cria um museu de arte infantil. E, depois da morte de Célestin Freinet, passa a dirigir o Institut coopératif de lécole moderne (Icem). Instituto que vai divulgar o trabalho da família Freinet para além do seu tempo e época.

\section{Pedagogia Freinet}

Célestin Freinet e Élise Freinet trabalham na elaboração pedagógica junto aos percursores da educação nova na França (1899-1939), os suíços, o divulgador da escola ativa Adolphe Ferriére (1879-1970), o neurologista da psicologia experimental Édouard Claparède (1873-1940) e o pedagogo Robert Dottrens (1893-1984) que defende o ensino individualizado e a educação democrática. O pedagogo Francês Roger Cousinet (1881-1973) investe no método de trabalho livre e em grupos (GAUTHIER; TARDIF, 2010).

Esses percursores movimentavam a pedagogia de Freinet na prática de uma educação que valorizava a autoformação e a atividade espontânea das crianças. Ele experimenta passeios com os alunos e após a vivência do passeio, os alunos escrevem textos livres. O espaço fora da sala de aula, em passeios e os textos produzidos a partir deles são parte da dinâmica e da construção da prática pedagógica que possibilita a expressão da aprendizagem de forma cooperativa sobre a influência do que se passa no cotidiano coletivo. Um exemplo desta prática e que Freinet organiza uma rede de correspondências entre diferentes escolas francesas e após estas ele decide coordenar a impressão da produção dos textos livres de onze classes para que os textos circulassem interescolas e entre as escolas. Sendo assim, esta é uma primeira parte da vasta produção da pedagogia de Freinet. 


\section{Escola Freinet}

Paralelamente a estes movimentos a Élise Freinet cria Coopérative de l'Enseignement Laïque (CEL). Ela organiza materiais pedagógicos e didáticos cunhando a pedagogia Freinet. E com estes materiais a instituição passa a ser divulgada e difundida na formação de professores franceses e também em outros países. O trabalho deste educador ganha rejeição junto aos espaços políticos conservadores da extrema direita e torna-se insustentável a relação entre o educador e os gestores políticos, da época. Assim, Freinet, em 1935, decide criar sua própria escola, em Vence, Le Pioulier. Ele inicialmente acolhe neste espaço os jovens moradoras dos bairros populares que vivem nas comunidades à margem de Paris, as crianças de parentes militantes do partido comunista e, mais tarde, agrega um grande número de refugiados espanhóis que desconhecem a língua francesa.

Investe em práticas de contrato de plano de trabalho individualizado, esta iniciativa foi inspirada nas ideias, que desde 1910, eram desenvolvidas pela educadora americana Helen Parkhurst, o pedagogo Robert Dottrens e o ideário do pedagogo Roger Cousinet (GAUTHIER e TARDIF, 2010). Este plano individualizado ocorre da seguinte maneira, as crianças, em sala de aula, se desenvolvem a partir de atividades individualizadas e atividades em grupos. As atividades individualizadas são orientadas a partir de um fichário de autocorreção e as atividades de grupo são desenvolvidas colaborativas e com objetivo preciso, por exemplo: a impressão do jornal. (SEBARROJA, 2003).

Este aparato de formação que potencializa as capacidades inventivas e participativas são parte das experiências e ideias pedagógicos de Freinet, que, por isto, foram sempre alvo de tensão entre as políticas de governo, até mesmo pelo fato dele fazer parte do pensamento comunista e de esquerda, posicionando-se opositor ao governo naqueles tempos.

\section{Método Freinet}

O Institut coopératif de l'école moderne (Icem) demarca que a pedagogia de Freinet acontece porque existe o método Freinet, porém em 1964, o próprio educador tenta retirar suas ideias pedagógicas desta armadura denominada como método Freinet. A armadura de método vai de encontro a própria proposta do educador. Ele para afirmar que sua pedagogia não produz regras rígidas, nem escalas e nem é aplicável por

RIAEE - Revista Ibero-Americana de Estudos em Educação, Araraquara, v.12, n.4, p. 2231-2244, out./dez. 2017. 
definições pré-estabelecidas defende que as condições didáticas dependem de contextos particulares e investe na didática de "invariantes pedagógicas" que são compostas por três pilares (FREINET, 1983): 1. A expressão livre, que é permitido dar as crianças o constante espaço de autoria da fala, do desenho, do gesto, da música, da escultura, etc. Este é um espaço de expressão que autoriza e que valoriza as produções das crianças. 2. A cooperação é oferecida para aprenderem a interagir com os colegas, as crianças atuam tanto como ouvintes como ensinantes dos seus pares. 3. As técnicas educativas são derivadas a partir da aprendizagem por tacteamento experimental: que correspondem aos processos convocados por o humano que aprende a fazer e, fazendo ele se engana e, erra e retoma seus erros progredindo. Ou seja, o investimento fundamental da pedagogia de Freinet é o tacteamento experimental vinculado ao método natural. Este fundamento experimental permite que cada criança se desenvolva de modo criativo em contato com sua potência de vida. Este modo favoriza o trabalho inventivo como parte do encontro com as potencialidades do meio social cooperativo, organizado e autogerido (SEBARROJA, 2003).

\section{Um pouco de Fernand Deligny}

Deligny produziu seu pensamento em educação por mais de cinquenta anos com práticas pedagógicas junto as crianças denominadas autistas que estavam à parte da sociedade. $\mathrm{Na}$ área da educação o trabalho deste pedagogo é pouco conhecido e traduzido no Brasil. Ele elabora seu trabalho metodológico cartográfico junto as crianças autistas a partir dos gestos cotidianos e retira deles uma experiência limite que ele a denomina de existência autística. Sendo assim, a produção deste autor permite que avancemos em estudos que priorizam mostrar as singularidades de uma produção pedagógica.

Levando em consideração estas informações e os investimentos acadêmicos, apresentamos o projeto de pesquisa intitulado: A linguagem e a pragmática da semiótica em rizoma: uma contribuição da filosofia da diferença na inovação das práticas escolares (MATOS, 2016a). Ele constitui uma das derivações do projeto de pós-doutoramento. Cabe destacar que o conceito de cartografia é empregado por outros pesquisadores e linhas de pesquisas. Mas queremos demarcar que o conceito de cartografia de Deligny (2013), ainda não foi efetivamente investigado como prática educacional e curricular no território da educação, no Brasil. Para chegarmos a fazer 
essa afirmação sistematizamos a procura de estudos sobre cartografia. Partimos para uma procura nos grandes bancos de dados de tese e dissertações da agência de fomento à pesquisa: CAPES. Utilizamos a palavra cartografia no espaço de procura em educação. Logo, num primeiro rastreamento, localizamos 77 trabalhos que porta este conceito, sejam eles, como metodologia de pesquisa e ou como conceito desenvolvido no corpo da pesquisa. Em nenhum desses trabalhos encontramos uma pesquisa sobre o tema das cartografias do pedagogo Deligny (2013).

Imediatamente passamos para os periódicos brasileiros, com os critérios estabelecidos no programa da agência CAPES, consideramos os produtos indexados como A1 e A2, em educação. Constatamos que o conceito de cartografia, era tratado a partir de alguns autores e linhas de pesquisas das teses anteriormente localizadas e outros ainda não citados anteriormente. $\mathrm{O}$ importante desta procura é que nos dirigimos aos textos localizados e todos eles tratavam do conceito de cartografia de outros autores e novamente nenhum deles sobre o trabalho pedagógico de cartografia de Deligny (2013).

Reiteramos a relevância deste texto em vistas ao que encontramos e não encontramos nos bancos de dados das teses, dissertações e nos periódicos mais qualificados e pela agência de fomento. Mas, também, relacionamos que a ausência de estudos sobre o tema da cartografia da obra do Deligny $(2007 ; 2013)$ se faz pouco ou nada presente, pois sua obra se encontra quase que totalmente em língua francesa ${ }^{2}$.

O terceiro argumento sobre a relevância da presença deste tema e autor na presente pesquisa, passa pela fasta produção intelectual dele, mas no Brasil, em 2015, somente um dos livros ${ }^{3}$ fora traduzido. Na França, após dez anos de sua morte se retomam as investigações e os estudos sobre sua obra. A partir de 2007, a editora francesa L'Arachnéen, publica um volume com algumas obras de Fernand Deligny e reedita outras. Seu trabalho, dito de maneira mais justa, o trabalho do grupo "aracniano" é registrado pela experiência de ensaísta, de poeta, de escritor e de cineasta. Sua obra é composta de vinte (20) livros entre 1944 a 2005, setenta e dois (72) textos e artigos entre 1933 a 2007 e ainda, no final dos anos 60, dirigiu um filme sobre o tema do cotidiano "aracniano", com o título Moindre geste, foi selecionado para a Semana da Crítica do Festival de Cannes, em 2004, sete anos após sua morte (DELIGNY, 2007).

${ }^{2}$ Localizamos doze (12) textos e quatro (4) livros traduzidos em Língua Italiana. Um (1) livro traduzido em Língua Alemã e outro em Espanhol.

${ }^{3}$ DELIGNY, Fernand. O aracniano e outros textos. Tradução Lara de Malimpesa. São Paulo: n-1 edições, 2015. Resenha do livro em Matos (2016).

RIAEE - Revista Ibero-Americana de Estudos em Educação, Araraquara, v.12, n.4, p. 2231-2244, out./dez. 2017. 
Porém, suas ideias pedagógicas começam a serem resgatadas em pesquisas, não somente no campo da educação, mas nas artes visuais e no cinema, abrindo-se assim um mercado editorial de larga circulação. Especificamente seu trabalho pedagógico entra em circulação na formação de professores porque as políticas governamentais se voltam fortemente para o tema da inclusão, da diferença e da educação especial. E, este pedagogo, desde 1947, é reconhecido como uma das referências pedagógicas inéditas de trabalho com crianças consideradas como inadaptadas ${ }^{4}$ socialmente e com limitação intelectual.

Neste espaço teórico e conceitual balizaremos uma rápida biografia do pedagogo Deligny, pelo fato de sua pedagogia ser pouco ou nada conhecida no Brasil. A seguir apresentamos o funcionamento do trabalho pedagógico em rede denominado como "aracniano" e a partir deste, destacamos o procedimento cartográfico e alguns dos seus possíveis elementos.

\section{Breve biografia do pedagogo}

Inicialmente descrevemos algumas linhas biográficas do educador francês Fernand Deligny (1913-1996). Mesmo sabendo que Deligny (2015) preferia ser chamado de poeta e de etólogo, priorizamos afirmar que ele era um pedagogo e produziu uma obra inclassificável, pois seu pensamento cruza os campos da filosofia, da educação, da arte e da literatura. Sua obra é composta por: desenhos, fotos, filmes, vídeos, poemas, diários, artigos, livros, cartas, fragmentos de textos, entrevistas, conferências e mapas.

Ele nunca se dedicou ao trabalho na universidade, seu trabalho de professor persiste por cinquenta anos de investigações e experiências na área da pedagogia. Delimitamos, didaticamente, duas fases $^{5}$ do seu trabalho, a primeira trata do seu trabalho junto a instituições de práticas educativas aos domínios de instituições públicas e a segunda, trata de quando ele se estabelece na região de Cévennes e constitui o grupo de trabalho denominado "aracniano", onde vai desenvolver o procedimento pedagógico cartográfico com a experiência autista.

\footnotetext{
${ }^{4}$ Optamos por preservar os vocabulários utilizado pelas políticas públicas e pelas instituições da época.

${ }^{5}$ Mesmo sabendo que temos estudos que mobilizam três fases do trabalho do autor (MIGUEL, 2016), para este texto, escolhemos o critério de dois moimentos: um dentro da instituição pública e outro fora dela.
}

RIAEE - Revista Ibero-Americana de Estudos em Educação, Araraquara, v.12, n.4, p.2231-2244, out./dez. 2017. 


\section{Primeiro movimento}

Entre 1938 a 1965, a primeira fase do trabalho de Deligny envolve o processo educativo junto as crianças e os jovens que eram classificadas como inadaptados, dementes e ou considerados à parte da sociedade (DELIGNY, 2015). Encontramos registros inéditos sobre sua experiência como educador no hôpital psychiatrique à Armentières, onde desenvolveu esse trabalho pedagógico, em meio a segunda guerra mundial. Nestes tempos viveu ele diz que "era professor primário encarregado de instruir crianças retardadas ${ }^{6}$ " (DELIGNY, 2015, p. 198). O pedagogo diz que a obrigação profissional, nestes tempos, era de sobreviver a ação dos homens em meio à guerra e também, diante de instruções instituídas por culturas institucionais. E, mesmo diante da guerra e das instituições a experiência do obrigatório se apresentava sem referente para estas crianças.

A partir desta experiência profissional ele transgrede as regras pedagógicas institucionais que obrigavam a participação em um sistema educativo punitivo que se voltava ao tratamento das crianças como dementes, retardadas e inadaptadas socialmente. Seu trabalho transgredia porque a prática educacional era inspirada em cordée $^{7}$, ou seja, ideia de uma corda ou linha que liga e organiza o funcionamento em forma de cooperação e dependência social não hierárquica, mas distributiva. Esta experiência foi denominada por ele como a experiência de la grande cordée (DELIGNY, 2007).

Este sistema de organização de trabalho pedagógico em cordée, se engajava em outra política pedagógica, mesmo dentro da instituição e do funcionamento institucional curricular que discrimina, marginaliza e quer adaptação. Sua pedagogia constituiu espaços de relações coletivas e não hierarquizantes. Como por exemplo a participação dos guardas e dos cuidadores nas atividades cotidianas em ateliês de arte, de escrita, de leitura, de atividades domésticas, de alimentação, de atividades esportivas e de jogos. Ele retirava o foco curricular do patológico social ou do biológico e imprimia a ação sóciopolítico de coparticipação e responsabilização institucional coletiva pelo processo pedagógico junto as crianças e os jovens.

${ }^{6}$ Lembramos que este termo era utilizado pela literatura cientifica dos anos 1940 . Deligny a usa para demarcar sua indignada posição a este tipo de posição institucional e curricular.

${ }^{7}$ Cordée é a ideia de um grupo de alpinistas reunidos por uma corda.

RIAEE - Revista Ibero-Americana de Estudos em Educação, Araraquara, v.12, n.4, p. 2231-2244, out./dez. 2017. 
Depois de muitas experimentações e embate político pedagógico junto as instituições educativas públicas, Deligny critica e tensiona sua relação contra as políticas de governo porque elas insistem em investir em discursos educativos de caráter adaptativo, com bases nas teorias biologistas, psicologizadoras e patológicas da época.

\section{Segundo movimento}

A partir de 1967, inspirado nas experimentações anteriores e principalmente na organização do cordée, o pedagogo já havia produzido uma considerável produção intelectual sobre seu trabalho pedagógico e decide se instalar com o grupo de crianças autistas, na região de Cévennes, no sul da França, constituindo um segundo movimento do seu trabalho e obra, que ele denominou “ aracniano” (DELIGNY, 2015).

Neste segundo movimento do seu trabalho ele investe fortemente em experimentações e investigações a partir do aporte conceitual da etologia, da etnologia e da antropologia. A proposição educativa e o trabalho pedagógico denominado “aracniano" advém destas áreas de estudos, em Cévennes.

Especificamente, a palavra "aracniano" carrega um tipo de organização do trabalho pedagógico neste local. O movimento "aracniano" se organiza inspirado nos estudos geométricos das teias das aranhas (TILQUIN, 1942). Funcionamento geométrico que derivou na elaboração de um procedimento cartográfico para acompanhar e investigar o cotidiano da "experiência autística" (DELIGNY, 2015). Este procedimento como parte do trabalho pedagógico deste grupo, na atualidade é considerado e reconhecido como um trabalho pedagógico inédito (MIGUEL, 2016).

Neste sentido cabe destacar que ele assumiu uma ação pedagógica institucional junto as políticas de governamentais e fora destas. Nos dois momentos de sua prática profissional, ele acaba por afrontar as instituições educativas que se centralizam em currículos que investem na adaptação das crianças numa sociedade competitiva, utilitarista e capitalista, que priorizam naturalizar o ensino das competências civilizatórias, sem questionar os valores de sociabilidade designados por elas mesmas.

A ação "aracniana" se distanciava cada vez mais das representações psicopatológicas e autoritárias. E, se aproximava da elaboração inventiva de outra política pedagógica produzida pela construção coletiva - rede "aracniana" - e pouco hierárquica, posição pedagógica anárquica para época e porque não dizer, para atualidade. 
Entretanto, levaremos em consideração mais o segundo momento da produção de Deligny, pois os objetivos e a problematização deste projeto de pesquisa estão direcionados para a cartografia como procedimento didático que se constituiu no funcionamento desta fase do trabalho dele. Considerando esta decisão de pesquisa, estaremos descrevendo brevemente o funcionamento "aracniano" como parte da organização do trabalho pedagógico e a cartografia como procedimento didático.

\section{Trabalho pedagógico "aracniano"}

A força conceitual da atuação "aracniana" é retirada e elaborada a partir dos estudos da etologia que estuda as espécies de animais, como as aranhas. Os principais autores que possibilitam esta aproximação entre etologia e educação foram os franceses, André Tilquin (1896-1968) na pesquisa sobre La toile géométrique des aragnées (1942), o etnólogo e o arqueólogo André Leroi-Gourhan (1911-1986) e o antropólogo Claude Lévi-Strauss (1908-2009). Com eles, o pedagogo Deligny e o grupo "aracniano", estudaram e elaboram uma organização de trabalho pedagógico, como a cartografia, que potencializa a singularidades da potência da experiência autista que aponta uma vivacidade desconhecida por nós, educadores (DELIGNY, 2015).

O trabalho pedagógico denominado de "aracniano" se constitui no coletivo e envolvem as crianças e os jovens autistas, as suas famílias e os educadores. Todos vivem no mesmo espaço rural. O terreno é dividido em pequenos acampamentos ${ }^{8}$, assim, cada um deles tecem uma participação singular fazendo funcionar a teia "aracniana".

A teia se transforma em uma rede que apreende pedagogicamente o agir autista. O objetivo do movimento "aracniano", como diz Deligny sobre seu trabalho: "O meu trabalho pedagógico: dar à palavra aracniano - ao meu ver estonteante - um sentido digno de sua harmonia e de sua amplitude". (DELIGNY, 2005, p. 22), ou seja, o trabalho pedagógico "aracniano" prioriza dar à palavra as singularidades da experiência autista (DELIGNY, 2015).

Como um "aracniano" a radicalidade de seu trabalho pedagógico passa pelo investimento de uma prática educativa que não se fecha no tema do autismo, mas ela

${ }^{8}$ Acampamentos em lugares como: Graniers (considerado réseau d'origine - rede de origem), Le Palais e Serret (torna-se o "laboratoire" da rede - laboratório no sentido de espaço dos mapas que geram as cartografias da rede). Estes acampamentos ficam alguns quilômetros uns dos outros, há troca, tanto de informações e investigação pedagógicas, quanto de sustentabilidade, como alimentos e mantimentos (DELIGNY, 2007).

RIAEE - Revista Ibero-Americana de Estudos em Educação, Araraquara, v.12, n.4, p. 2231-2244, out./dez. 2017. 
passa pela possibilidade de extrairmos uma prática que tem o compromisso político com a singularização com o outro; o outro no processo educativo não pode ser reduzido as teorias psicológicas, nem a dominação dos universais da linguagem sobre o campo da individualização. Sendo que, a ação deste compromisso com o outro é composta pela ação didática que se expressa numa singularização da leitura das cartografias que ele faz junto do cotidiano dos autistas e dos moradores dos acampamentos.

Podemos definir este pensamento como uma prática única que nos ensina a extrair uma pedagogia que se faz junto a singularização e a apreensão da existência com o outro. Uma experiência de múltiplos modos de existir com o agir e não sobre (imposição do logos para interpretar e classificar) o agir do outro.

\section{Procedimento cartográfico e seus elementos}

O trabalho pedagógico "aracniano" acontece a partir da sustentabilidade e coletividade participativa em pequena rede ou teia que vive em presença próxima de crianças autistas. E, para dar à palavra aos movimentos deste trabalho, eles, inicialmente, determinam acompanhar os movimentos de todos os moradores dos acampamentos.

Logo, percebem que existia um funcionamento espacial e se interessam em acompanhar o movimento e atividades dos moradores determinados pela ciência como autistas. Necessitam registrar estes movimentos, assim, investiram em registro topográfico que era feito em folhas brancas preenchidas conforme os movimentos espaciais do deslocamento cotidiano de todos os moradores dos acampamentos.

Avançaram em seus estudos topográficos investindo em símbolos e glossários que exprimissem o que se passava nestes espaços. Os símbolos destes estudos formavam traços específicos e demarcavam as linhas de "áreas de estar" (DELIGNY, 2015, p. 159), que eram as linhas que apontavam para o modo de funcionamento das crianças e dos jovens autistas.

Deligny (2015) afirma a relevância do registro do espaço físico - estudo topológico - e para isto cria mapas como parte deste registro denominando o de registro topográfico. Os estudos topológicos estavam presentes nas topografias que se tornaram mapas da montagem de um procedimento cartográfico.

Por meio da sistemática topográfica foi possível a elaboração de mapas dos traços de um agir autista (DELIGNY, 2015) desconhecido pelas clássicas instituições

RIAEE - Revista Ibero-Americana de Estudos em Educação, Araraquara, v.12, n.4, p.2231-2244, out./dez. 2017 
educativas. Com este procedimento produziu-se inúmeros mapas que também contém traços da experiência pedagógica que se efetiva, junto ao movimento "aracniano".

As análises dos mapas descrevem o andar, os gestos, os afetos, a linguagem, o estilo de existência e,

O mapa é aberto, é conectável em todas as suas dimensões, desmontável, reversível, suscetível de receber modificações constantemente. Ele pode ser rasgado, revertido, adaptar-se a montagens de qualquer natureza, ser preparado por um indivíduo, um grupo, uma formação social. Pode-se desenhá-lo numa parede, concebê-lo como obra de arte, construí-lo como uma ação política" (DELEUZE; GUATTARI, 1995, p. 45).

A cartografia e seus mapas podem serem considerados como procedimentos didáticos pedagógico porque ela constitui um conjunto de mapas que são compostos pelas linhas e outros símbolos que capturam o movimento das "crianças, cujos trajetos são traçados [...]" (DELIGNY,2015, p. 157). Os mapas, também exprimem a experiência das "linhas de errância de crianças 'autistas"” (DELIGNY, 2015, p. 41) e os traços de linhas do trajeto dos adultos, no mapa, são identificados como "os traços costumeiros 9 "” (DELIGNY, 2013). Os mapas são efeitos de uma montagem cartográfica e que podemos associar como parte de uma organização do trabalho pedagógico “aracniano". Para acessarmos a leitura cartográfica dos mapas necessitamos acessar o plano semiótico "aracniano", tais como: linhas, anel, traço, ângulo, entrelinhas, desvio, deriva, presença próxima, gesto por nada, etc. Os mapas são efeitos de sentido de uma ação política age pela singularidade em educação e que, assim, resiste ao pensamento das instituições que maquinam e são maquinadas pelo funcionamento das sociedades disciplinares e de controle.

\section{Considerações finais}

Dito isto, compreendemos e reconhecemos que o funcionamento das pedagogias de Freinet e Deligny desafiam a prática educativa como política de resistência a reprodução do ato pedagógico acomodados nas políticas da sociedade do disciplinamento e da adaptação. Eles fizerem enfrentamentos a sua sociedade e com eles poderemos criar espaços de pensamento e experimentação para enfrentarmos nossos

${ }^{9}$ Tradução livre.

RIAEE - Revista Ibero-Americana de Estudos em Educação, Araraquara, v.12, n.4, p. 2231-2244, out./dez. 2017. 
tempos de sociedade de controle, de competitividade e da aceleração pelo consumismo. Ao investirmos nesta homenagem acreditamos que resistiremos a entrega do processo de ensino e da aprendizagem ao desempenho "cognitivo e neurocientífico" (HAN, 2015) e, com isso, resistiremos a reprodução do modo de funcionamento cientificista que produz "cansaço tecnocientífico" (HAN, 2015) aos educadores e pesquisadores em pedagogia.

\section{REFERÊNCIAS}

DELEUZE, Gilles.; GUATTARI, Felix. Mil platôs. Capitalismo e esquizofrenia. Vol.1. Tradução de Aurélio Guerra Neto e Célia Pinto Costa. São Paulo: Editora 34, 1995.

DELIGNY, Fernand. O aracniano e outros textos Tradução Lara de Malimpesa. São Paulo: n-1 edições, 2015.

DELIGNY, Fernand. Cartes et lignes d'errer. Trace du réseau de Fernand Deligny. 1969-1979. Conception Editoriale Sandra Alvarez de Toledo. Paris: Les Éditions de l'Arachnéen, 2013.

DELIGNY, Fernand. Fernand Deligny œvres. Édition établie et présentée par Sandra Alvarez de Toledo. Paris: Les Éditions L’Arachnéen, 2007.

FREINET, Elisa. O itinerário de Célestin Freinet :. a expressão livre na pedagogia Freinet. Tradução de Manoel Dias Duarte. Portugal, Lisboa: Livros Horizontes, 1983.

GAUTHIER, Clermont; TARDIF, Maurice. A pedagogia: teorias e práticas da antiguidade aos nossos dias. Tradução de Lucy Magalhães. Petrópolis, RJ: Vozes, 2010.

HAN, Byung-Chul. Sociedade do cansaço. Tradução de Enio Paulo Giachini. Petrópolis: Vozes, 2015.

MATOS, Sônia Regina da Luz. O pedagogo francês Fernand Deligny (1913-1996) e a sensibilidade estética da existência autista. Revista Entreideias: educação, cultura e sociedade. Salvador, v. 5, n. 2, p. 97-102, jul./dez. 2016.

MATOS, Sônia Regina da Luz. Projeto A linguagem e a pragmática da semiótica em rizoma: uma contribuição da filosofia da diferença na inovação das práticas escolares. CAPES - Coordenação de Aperfeiçoamento de Pessoal de Nível Superior (CAPES). Portaria 36/2013. Estágio Pós-doutoral. Chamada II 2015. Processo: 000646/2015-06. 2016a.

MIGUEL, Marlon Cardoso Pinto. La marge et hors-champ. L'humain dans la pensée de Fernand Dligny. Tese de Doutorado em Cotutela. Université Saint-Denis 
Paris 8, Arts Plastiques et de Philosophie. Universidade Federal do Rio de Janeiro, Programa de Pós-Graduação em Filosofia. 2016. 617 f.

RABAT, Janine. Hommage à Fernand Deligny. Revue Vers l'Education Nouvelle. $\mathrm{n}^{\circ} 479,1997$.

SEBARROJA, Jaume Carbonell. (Org.). Célestin Freinet. Pesquisar e cooperar. In:

Pedagogias do século XX. Porto Alegre: Artmed, 2003, p. 73-84.

TILQUIN, André. La toile géométrique des araignées. Paris: Presses Universitaires de France, 1942.

\section{Como referenciar este artigo}

MATOS, Sônia Regina da Luz. Os educadores franceses Célestin Freinet e Fernand Deligny. Revista Ibero-Americana de Estudos em Educação, Araraquara, v. 12, n. 4, p. 2231-2244, out./dez. 2017. Disponível em: <http://dx.doi.org/10.21723/riaee.v12.n4.out./dez.2017.9637>. E-ISSN: 1982-5587.

Submetido em: 01/07/2017

Aprovado em: 30/11/2017 